Canadian Journal of Family and Youth, 7(1), 2015, pp 1-26

ISSN 1718-9748 @ University of Alberta

http://ejournals.library.ualberta.ca/index/php/cjfy

\title{
Is there a Care Gap for Young Carers in Canada? Edmonton Community Agencies' Perspectives
}

\author{
Waugh, E., Szafran, O., Duerksen, K., Torti, J., Charles, G. \& Shankar J.
}

\begin{abstract}
This paper presents the findings of a study exploring the perspectives of community agencies in Edmonton, Alberta on issues related to young carers (young people who are primary caregivers to a family member or friend who is ill, disabled, or has other conditions needing care or support). Four themes emerged from the qualitative research: lack or awareness and recognition of young carers; language and terminology used to label young carers; lack of community support; and the need for policy development relevant to young carers. The study draws attention to a group of young people who remain hidden and unrecognized in Canadian society.
\end{abstract}

Earle Waugh, $\mathrm{PhD}$, is Professor Emeritus in Religious Studies, Office of Interdisciplinary Studies, Faculty of Arts, and Director of the Centre for Culture and Health, Department of Family Medicine, Faculty of Medicine and Dentistry, University of Alberta. He is also a former Director of Education for the Alberta Caregivers Association. He has published widely on the topic of intercultural understanding, particularly in Aboriginal and Islamic contexts. Olga Szafran, MHSA, is Associate Director of Research, Department of Family Medicine, University of Alberta. She has conducted family practice research in the areas of practice patterns of family physicians, medical education, international medical graduates, culture and medicine, and primary health services research, and has published in these areas. She co-edited the book At the Interface of Culture and Medicine (2011) published by the University of Alberta Press. Kimberley Duerksen, MSc, is Research Coordinator in the Department of Family Medicine, University of Alberta. She has a background in pharmacology and has worked in family medicine research for the past six years. She has an interest in qualitative and quantitative methodology and is interested in all facets of research related to family medicine. Jacqueline Torti, is a PhD candidate in the School of Public Health, University of Alberta. She is a qualitative methodologist whose research interests lie in the areas of public health sciences and family medicine. She teaches a graduate level course on psychosocial perspectives on health in theory research and practice. Grant Charles, PhD, is Associate Professor in the School of Social Work at the University of British Columbia and Affiliated Associate Professor with the Division of Adolescent Health and Medicine at the British Columbia Children's Hospital. He is also lead of the British Columbia Young Carers Research Project. He has published a number of articles on his work with young carers including Young Carers in Canada: The Hidden Costs and Benefits of Young Caregiving with the Vanier Institute of the Family. Janki Shankar, PhD, is Associate Professor, Department of Social Work, University of Calgary. She teaches in the areas of mental health and addictions, oppression, diversity and social justice, qualitative research and field practice at graduate and undergraduate levels. She has published in the areas of mental health of employees and postsecondary students, support needs of employers, domestic violence in visible minority immigrant families, needs of family caregivers of people experiencing disability.

Acknowledgements: This study was funded by the Alberta Centre for Child, Family \& Community Research. 
Waugh et al.

\section{Introduction}

Family caregiving has been the concern of researchers and policy makers for over three decades (Canadian Caregiver Coalition, 2012) with increasingly sophisticated analyses of caregiving roles (Giesbrecht, Crooks, Williams \& Hankivsky, 2012), multicultural implications (Kelly \& Minty, 2007), disability type (Schulz \& Quitter, 1998), caregiver health impact (Schulz \& Beach, 1999), and family life (Fast, Highan, Keating, Dosman \& Eales, 2012; Avison, Turner, Noh \& Speechley, 1993); however the examination of young people performing such care is in its infancy. Young carers are young people who take on substantial caring responsibilities for family members and significant others because someone in the home has a chronic illness, disability, mental health issue, and/or substance abuse problem. While well recognized in the United Kingdom and Australia, young carers are largely an unstudied population in Canada (Becker 2007; Aldridge \& Becker, 1999). To our knowledge, our study is the first study on young carers in the Edmonton area.

\section{Defining Young Carers}

Considerable variability exists in defining the young carer population, partly related to the issue of what is or is not considered to be family caring responsibilities for young people. Providing general help around the home and caring for others is expected and held to bring positive value to young people's healthy upbringing in most families (Charles, Stainton \& Marshall, 2012). Acting as the primary caregiver (individual who takes primary responsibility for the caring duties) for a family member is, however, generally considered to be beyond the norm of what would be developmentally, socially and culturally expected of young people (Aldridge \& Becker, 1999; Charles et al., 2012). While generally accepted that there should be differences between the caring contributions of adults and young people in a family, exactly 
defining the differences can be difficult. This has led to a variation of definitions of young caring. For example, Becker (2000) defines young carers as:

children and young persons under 18 who provide or intend to provide care, assistance, or support to another family member. They carry out, often on a regular basis, significant or substantial caring tasks and assume a level of responsibility that would normally be associated with an adult. The person receiving care is often a parent but can be a sibling, grandparent or other relative who is disabled, has some chronic illness, mental health problem or other condition connected with a need for care, support or supervision. (p. 378)

Charles (2014) has expanded the definition of young carers as being:

A person under the age of 25 who is a significant caregiver in a family due to a parental illness, addiction, disability or absences and who takes on responsibilities beyond what would be expected given cultural norms and age. (p. 1)

These definitions cite significant and substantial caring tasks, and point to the need for care or supervision for an adult in the family. Yet, substantial caring tasks may have ethnic, local or gender-related qualifiers and the need for care or supervision may have a cultural component that varies considerably across groups. Defining young carers is further complicated by other factors, including the debate on the upper age range of caregiving, as well as reaching consensus on what is developmentally and culturally appropriate. The general lack of awareness of young carers in Canada also means that many young carers do not self-identifying with this terminology (Beards \& Barua, 2011; Richardson, Jinks \& Roberts, 2009) because they do not recognize the extent of their caring responsibilities.

\section{Prevalence of Young Carers}

No national prevalence data have been collected on young cares in Canada to date; however, a study conducted in an urban secondary school in British Columbia reported that $12 \%$ of young people took on significant caregiving roles in their family (Charles, Marshall \& Stainton, 2010). Approximately $40 \%$ of the young carers reported providing care for a parent(s), 
Waugh et al.

$36 \%$ for a grandparent, $7 \%$ for an aunt/uncle, and the remaining $17 \%$ for another family member.

Surveys in other countries have found lower prevalence rates. A national omnibus survey of 2000 households in the United States found that 3.2\% of homes with young people reported having a young carer between 8 to 18 years of age (Becker, 2007; Hunt, Levine \& Naiditch, 2005). This translates into an estimation of approximately 1.4 million young carers in the USA. Estimates in the United Kingdom range from approximately 3\% to 8\% (Aldridge \& Becker, 1993; Shifren \& Kachorek, 2003; Stewart \& Patterson, 2010). The prevalence in Australia is between $3.6 \%$ to $7.4 \%$ depending upon the age range used in the survey (Pakenham, Chiu, Bursnall \& Cannon, 2007).

It is difficult to assess the actual prevalence rates of young carers in view of definitional and methodological problems with collecting data. Some jurisdictions include only people up to 18 years of age, while others include young people up to age 25 . Who is surveyed also appears to influence prevalence estimations. The original UK data were collected through the national census completed by adults, which may have an underreporting bias, as adults may have a vested interest in not reporting the struggles present in their families which result in their children being young carers. Jurisdictions where young people were asked directly about whether they take on caregiving roles report a much higher prevalence rate (Charles et al., 2010).

Young people may also not openly identify as being young carers because they fear stigmatization and external interference into their family life (Banks et al., 2002; Richardson et al., 2009). Family solidarity and legitimate contributions to family wellbeing may militate against a separate identity as 'carers', since their roles are deemed normal within their own individual family situation. These issues may be related to caregiving in general, since research has shown that many of the same concerns apply to all informal caregivers (Bittman, Fast, Fisher 
\& Thomson, 2004). Identifying as young carers may be particularly difficult for youth whose public perception is not associated with roles related to caring (Fast et al., 2005; Lackey \& Gates, 2001) and whose position in society is not assigned to a public sector jurisdiction (Jenkins \& Wingate, 1994). Such issues as the protection of family privacy, a lack of societal awareness of the existence of young carers, methodological issues with data collection, and the varying definitions of the term means that prevalence rates need to be interpreted with caution.

The actual and reported number of young carers is likely to increase due to societal changes. With the increase in chronic diseases and disabilities associated with more people living longer (Lackey \& Gates, 2001), the upcoming generation of youth will be impacted by an aging baby boomer population and the high prevalence of care associated with this transition. Family dynamics are also shifting considerably, with many more single-parent families and more families pursuing work outside the home, thus increasing the probability of young people becoming the primary caregiver in the home (Lackey \& Gates, 2001; Siskowski, 2006). As more women work, pursue higher levels of education, and delay childbearing to later ages, this may lead to greater instances of even younger children caring for their aged parents or grandparents (Shifren \& Kachorek, 2003). Moreover, as family size continues to decrease, fewer people will be available to meet extraordinary family needs, resulting in more age-inappropriate responsibilities likely to fall onto young people (Charles et al., 2012).

\section{Responsibilities of Young Carers}

Becoming a young carer typically starts with the onset of an illness, disease or a deteriorating chronic condition or situation in the immediate family that leaves a young person with little choice but to become, at least temporarily, the primary caregiver within the home (Aldridge, 2008; Metzing-Blau \& Schnepp, 2008). Young carers may take on a wide range of 
Waugh et al.

caregiving tasks, depending on the situation in the home and the severity of the family member's illness. These tasks may include domestic duties, physical tasks, medical care, and intimate care.

Domestic duties may include child care (Banks et al, 2001; Barber \& Siskowski, 2008), household management (running errands, grocery shopping, cleaning the house, cooking meals, washing dishes, or doing laundry) (Beards \& Barua, 2011; Gates \& Lackey, 1998; Warren, 2007), managing finances, and handling the care recipients' personal affairs (Barber \&

Siskowski, 2008; Beards \& Barua, 2011). Physical tasks may entail assisting the care recipient with tasks of daily living (Gates \& Lackey, 1998), including helping the care recipient around the house, in and out of bed, assisting with a wheelchair, as well as seeing or hearing for those who are blind or deaf (Becker, 2007; McClure, 2001). Intimate care may involve providing emotional support and comforting the care recipient (Banks et al., 2001; Gates \& Lackey, 1998), praying with and reading to those in need, providing company (Lackey \& Gates, 2001; Warren, 2007), as well as personal care such as dressing and undressing, bathing, toileting, showering, and feeding (Barber \& Siskowski, 2008; Beards \& Barua, 2011; Gates \& Lackey, 1998; Smyth, Baxland \& Cass, 2011). Medical tasks may include administering or supervising medication (Banks et al., 2001; Becker, Dearden \& Aldridge, 2000; Gates \& Lackey,1998), catheter care, and cleaning and dressing wounds (Lackey \& Gates, 2001; Warren, 2007). In immigrant families or families who do not speak the dominant language, young people may translate conversations that take place in medical settings, exposing them to content well beyond their age (Barber $\&$ Siskowski, 2008; Charles, Stainton \& Marshall, 2011; Diaz, Siskowski \& Connors, 2007). Such caregiving responsibilities have been shown to have potentially both positive and negative consequences for caregivers (Morse, Shaffer, Williamson, Dooley \& Schulz, 2012). One of the advantages that may occur from being a young carer is the intimate bond that the young person 
may share with the person for whom they are caring. Young carers may develop deep personal relations at a level that would otherwise be unattainable without the experience of being the primary carer for that individual (Chaparro, 2011). These strong relationships and attachments can often offset some of the negative emotional implications associated with young caregiving (Aldridge, 2008; Aldridge \& Becker, 2003; Banks et al., 2001). These relations can result in a type of enduring love for the one they care for, along with a sense of responsibility and loyalty to that individual (McClure, 2001).

Young carers do, however, experience many challenges. Given the amount of time these young people spend caring for another person, they are often late or absent from school and some even end up delaying their education or dropping out altogether (Charles et al., 2012). Young carers also have little time to complete homework or study due to their after-school caring duties. They reportedly lack concentration while in school (many are consumed with thoughts of the loved one that they are caring for), and therefore their school performance and grades tend to suffer (Aldridge, 2008; Banks et al., 2001; McClure, 2001). Negative social implications may also be a consequence of being a young carer. When young people are consumed by the restrictive and time-consuming nature of their caring tasks, they do not really have the opportunity to just be kids, with all that entails in terms of play time, free association with other youth, and social engagement in team sports and extra-curricular activities (Banks et al., 2001; Gates \& Lackey, 1998). Due to their caregiving responsibilities, young carers may have limited access to social networks outside of their home/school, therefore, not get the opportunity to play on sports teams and participate in social and extracurricular activities (Aldridge, 2008; Banks et al., 2001; Becker, 2007). Both the mental and physical health of young carers can also suffer as a result of their caregiving roles. Young carers often have psychological 
Waugh et al.

or emotional problems including maladaptive psychological impairments, troubling adjusting, low self-efficacy, poor confidence and/or depression (Aldridge, 2008; Banks et al., 2001; Moore, McArthur \& Noble-Carr, 2011; Taylor \& Fuggle, 2001). Young carers often compromise their growth and development when they attempt to lift or assist family members around the house (Aldridge, 2008; Barber \& Siskowski, 2008), which can lead to injuries and an increased risk of back problems in later life (Thomas et al., 2003). Ultimately, the consequences for the young carer depends upon the family circumstances and the quality of the relationship between family members (Yasmin, Charles \& Marshall, 2012).

\section{Social Policies for Young Carers}

In Canada, there is lack of public discourse on young carers, little recognition of young carers among the general public, policy makers and professionals (Charles et al., 2012), and scant policy development in this area. There has also been limited research on young carers, hence, few supports and services available to young carers in Canada. In contrast, the United Kingdom and Australia have made substantial progress on young carer policies and some policy development has occurred in Germany and Spain (Aldridge, 2008). In the UK, legislators, policymakers and professionals have formally recognized young carers to the degree that they have specific legal rights, supporting health and social care policy, and established local and national support services (Becker, 2007; Aldridge \& Becker, 1999). In 1990 in the UK, the National Health Service Community Care Act was established recognizing that support for carers, including young carers, is a national priority (Dearden \& Becker, 1997). In 1999, an entire chapter of the National Strategies for Carers in the UK was dedicated to young carers (Becker, 2007; Cormac \& Tihanyi, 2006). While not as advanced as the UK with respect to young carer initiatives, Australia has made considerable progress in granting young carers partial 
Care Gap for Young Carers

rights in some parts of the country, as well as some established supports and services (Becker, 2007).

As for Edmonton, young carers did not appear at all in Kinley and Kolkmans’ (2009) study of social wellbeing in the city; a source that addresses social health and neighbourhood wellbeing. Anecdotal evidence suggested that young people who provide care to a family member were prevalent in the population; however, there were no published studies of this cohort relevant to the city. Hence, our study arose out of an evident gap in local research on an important group of young people.

\section{Study Purpose and Methodology}

The purpose of this study was to explore the experiences of community agencies with young carers in the Edmonton area. The research inquiry arose from previous work of the principal investigator with the Alberta Caregivers Association (ACA), which provides support to adult caregivers, however, had no established programs for young carers at the time. A young carer came to the attention of the ACA, which raised the question of whether other community agencies dealt with and/or provided supports to young carers.

The study was conducted in the western Canadian city of Edmonton, Alberta. In 2011, the population of the census metropolitan area of Edmonton was 1,159,869, with 205,520 (17.7\%) being young people aged 5-19 years (Statistics Canada, 2011). Of the 316,575 census families, $15.9 \%(50,350)$ were lone-parent families. The prevalence of young carers has been reported to be higher in single-parent than two-parent families (Aldridge, 2008). In Edmonton, $21.3 \%$ of the population reported a mother tongue other than English or French. Immigrant families may lack social supports and connectivity with the larger community and cultural 
Waugh et al.

norms/expectations may place greater caregiving responsibilities on children (Merrell, Kinsella, Murphy, Philpin \& Ali, 2005). According to the 2006 census, 15.2\% of Canadians reported having a one or more disabilities (Statistics Canada, 2006). The probability of caregiving increases with the presence of disability in the home (Barber \& Siskowski, 2008). Given these demographics, it was expected that young carers would be prevalent in the Edmonton area and that community agencies would be in contact with them.

Twenty nonprofit community agencies were invited by means of an invitation letter to take part in a one-day meeting. The meeting, held on January 20, 2012 from 8:00 am to 3:30 pm, was comprised of several presentations, but primarily involved small group discussions. The study used group discussion methodology to identify the degree to which local area community agencies were familiar with the issues and needs of young carers, availability of support programs, and related policy issues. While similar to a focus group and not as narrowly focused, the group discussion involves an interactive group conversation with participants in order to achieve understanding on a topic/issue through interpretation in the context of what participants say and of the group process, not just the literal meaning (The Association for Qualitative Research, 2013). The group discussion method was selected because it is a useful social research tool to explore participants' initial perceptions and allow participants to express any concerns they may have during the exploratory phase of a study (Payne \& Payne, 2013).

Three members of the research team moderated the meeting and the discussion groups. Presiding over the meeting entailed keeping on-track with the agenda items. Moderating the discussion groups involved ensuring that the group discussed all the specified questions during the designated time. In the semi-structured discussion groups, participants were asked to provide their perspectives on the issues and needs of young carers, as well as the supports required and 
Care Gap for Young Carers

policy implications. The main questions were: (1) What issues do young caregivers in our community face? (2) What are the needs of young caregivers? (3) What types of programs would be beneficial to young caregivers? and (4) What policy issues should be addressed?

To facilitate more open dialogue, the discussion groups were not audiotaped, but rather three members of the research team took notes. The notes were typed and subsequently analyzed descriptively for theme areas and interpretively for participants' perspectives by four members of the study team. The team met three times to arrive at a consensus of the main themes.

The study received ethics approval from the Health Research Ethics Board, University of Alberta.

\section{Results}

Nine agencies (11 individuals) participated in the one-day meeting and discussion groups. The community agencies included: Alberta Caregivers Association (ACA); Alberta Alliance on Mental Illness and Mental Health (ALMIMH); Amyotrophic Lateral Sclerosis (ALS) Society of Alberta; Boys and Girls Club of Edmonton; Canadian Paraplegic Association (Alberta); CASA (Child, Adolescent and Family Mental Health) Child, Adolescent and Family Mental Health; Gateway Association for Community Living; Multiple Sclerosis (MS) Society of Canada (Edmonton); The Parkinson Society of Alberta. Each of the agencies offered support to individuals with a particular disease, illness or disability and were expected to encounter young carers through the services they provided. While the participants initially did not recognize young carers as distinct clients of their agency, they subsequently acknowledged that young carers were indeed peripheral to their service programs. One of the participants had a child with a disability, thus had personal experience with being a caregiver. 
Waugh et al.

Findings from the group discussion with community agencies were categorized into four theme areas: lack of awareness and recognition of young carers; language/terminology used to identify young carers; lack of community support programs for young carers; and policy development. A summary of each theme areas follows.

\section{Lack of Awareness \& Recognition}

During the group discussion, participants expressed that a general societal awareness and recognition of young caregivers was needed in Canada. Young people who provide care remained a hidden population and were not a primary focus for most agencies. Most agencies did not keep statistics on the number of young carers seen, but suspected that there were many such young people within the community, given the types of individuals and families the agencies served. The agencies noted that it would be important for young carers to identify themselves and for friends, family, and communities to be aware of the prevalence of and issues faced by young carers. Young carers were perceived as being invisible, often with feelings of isolation stemming from a lack of awareness of their existence in the community. Agencies acknowledged that their staff were in need of education related to the issues and needs of young carers and how to recognize and address issues when they arise.

\section{Language/Terminology}

Some agency participants had not previously heard of the terms 'young carer' or 'young caregiver' and thus agencies did not categorize them as carers per se. 'Young caregiver' is an adaptation of the general term used for family and relatives who care for a chronically-ill family member, while 'young carer' signals the informal attendance and support offered by an underaged member of the family to a chronically ill family member. One participant stated that "Caregiving is not a language that is used in our home;" it is usually disguised as providing 
Care Gap for Young Carers

support or help. There was discussion about the value in using this term and the value of labeling young people as young carers.

The theme of language/terminology also transmuted into other terms that may be associated with caregiving. Some felt these terms were too medical and did not resonate well with young carers and suggested the terminology surrounding young carers should be made more age-appropriate and child friendly. For example, the term 'respite' was perceived to be medicalized and did not appeal well to young people. Defining terminology that can serve as common ground for young carers was deemed essential. Participants reached a general consensus that the term 'young carer' was less intimidating and less threatening than 'young caregiver.'

It was noted that the term 'young carer' is uncommon within the Canadian context. The group expressed mixed opinions on this issue. On one hand, identifying and labeling young carers could result in positive changes, such as: recognizing the role that these young people play; identifying their needs; creating a "voice" and giving them the opportunity to be heard; providing a way to connect them to various services; and providing a way for people to connect, giving them a common term that they can identify with. Conversely, labeling an individual as a young carer could have a negative impact by medicalizing the way the young carer or the care recipient view the caregiving relationship. If the care recipient does not identify or respect that they are in need of care, then what effect would this have on the individual identified as the young carer? The group reflected that it was important to consider the effect that the terminology would have on the caregiving relationship. 
Waugh et al.

\section{Lack of Community Support}

The acknowledgement of the lack of community support for young carers stemmed from a discussion of their perceived needs. Community agencies identified three main categories of needs of young carers: (a) educational needs (teacher understanding and flexibility regarding homework/assignment deadlines, availability of tutors, special financing and bursaries for higher education, breakfast/lunch programs at school); (b) informational needs (basic life skills cooking, cleaning, banking, etc.), information on medical conditions geared toward youth, information about being a young carer directed at teachers, health professionals, counselors, and community organizations; and (c) service needs (transportation, meal preparation, housekeeping, counseling, respite care). While participants agreed that young carers needed to be supported within the local community, the agencies noted that they did not have resources/programs specifically designed for young carers, nor were staff trained to provide support to such vulnerable young people.

While a few Edmonton agencies offered either phone support that young carers could access or an online forum for young people to chat with other young people who have a family member with a specific disease. Some offered a summer camp program for young people whose parent or family member had a debilitating condition. It was evident that programs available to young carers were scant in the community, and while some were targeted at young people, none were specifically designed for young carers. The group consensus was that if resources were available to support young carers, then this population would be more visible in the community. Participants felt that a care gap existed at least partly because these young people were not identified as requiring assistance. 
Participants identified a number of new initiatives that could be developed for young carers and their families. It was noted that young carers should have the opportunity just to be young people; to run, laugh, play, have fun, and set aside time to not worry about their caregiving responsibilities. Suggestions focused on developing recreational programs such as camps, after-school programs, arts and crafts, and sporting opportunities. Lack of transportation was identified as a barrier to accessing recreational opportunities, thus subsidized taxi rides, volunteer drivers, or bussing programs designed for young carers were suggested as potential solutions. Part of the discussion surrounding the need for transportation arose from the group's perception that young carers were more prevalent in low income families; hence, one of the ideas addressed was the need for financial assistance and paying young carers for their services and offering bursaries. Other potential program ideas included 'respite' care programs, social networking, and peer counselling.

\section{Policy Development}

Agency participants discussed a number of policy ideas relevant to young carers. For many, the situation pointed to the need to improve communication, collaboration, and partnerships between community agencies in creating young carer policies. Participants stressed for the need for community agencies to work together and advocate for change. Agencies readily acknowledged that many organizational boundaries and barriers would need to be broken down to facilitate communication and collaboration. They maintained that eliminating the silo method of operating as distinctive organizations would create positive policy change and move forward community partnerships and support for young carers, thereby, enabling agencies to share limited resources and train staff collectively. They also spoke of the lack of representation of young carers at the policymaking level and suggested the need to incorporate the values and 
Waugh et al.

perspectives of young carers into the development of effective policies. There were even some suggestions that existing governmental and institutional policies could force young carers to remain underground because of funding and other legal issues. Overall, there was general agreement that the most pressing matter was to conduct a needs assessment of young carers and to determine what resources should be developed and how best young carers can be served by public institutions and community organizations.

\section{Discussion}

Our study involving community agency perspectives on young carers suggests that young carers are invisible, unrecognized, and lack support systems and policies within the Canadian context. Currently, Canada is lagging behind other countries in recognizing and supporting young carers. It is likely that a number of factors have contributed to Canada's slow progress in this area, including: public availability of social supports for disabled and ill persons; the absence of a major national tragedy (eg. war) in the past century that would compel young people to provide more family support; the preponderance of the nuclear family unit with grandparents living independently; and the relatively young age of the population. The paucity of Canadian research on young carers may also be impeding community and policy progress in this area. As such, young carers are currently not on the radar of community agencies in our country.

As Canada's population ages and with continued influx of immigrants into the country, issues related to young carers are expected to grow. In some immigrant communities it is considered a filial duty of the children to care for sick and aged parents/elders and long-term care facilities may not be culturally acceptable for family members with disabilities, therefore, the care of these relatives may fall on young people (Merrell et al., 2004). Many immigrant families 
do not access external support services either due to lack of knowledge or fear of mainstream cultural practices. There is also evidence that immigrant children from low socio-economic families provide care for their younger siblings in the absence of their parents who may be working long hours (Charles, Staiton \& Marshall, 2009). Immigrant young carers may also experience more difficulties in school compared to their mainstream counterparts because of racism and cultural differences (Charles et al., 2009). The participants in our study also perceived young carers to be more prevalent in low income families, which is supported by the literature (Cass, Smith, Hill, Blaxland \& Hamilton, 2009; Ridge, 2011). Young carers from families of lower socio-economic status may have fewer available resources and lack social supports.

The finding that community agencies lacked awareness and recognition of young carers reflects the state of the issue in Canadian society. If young carers remain hidden and there is no societal recognition of this group, community agencies do not develop programs aimed at young carers. Moreover, staff education is necessary to recognize and address young carer issues and needs. The lack of recognition of young carers is associated with no support programs being developed, which in turn results in the full weight of the caring burden continuing to fall on these young people. When the needs of young carers are poorly acknowledged and there are no social supports, the burden on young people can be overwhelming, forcing them to suffer in silence. Without recognition, neither schools nor parents are able to argue for support for young carers, organizations cannot develop programs aimed at this group, and community resources cannot be leveraged to address their needs.

There were genuine concerns among the agencies dealing with children that an expansion of their role to include this cohort could have a marked effect on current programs, since their 
Waugh et al.

resources were already fully engaged. Agencies were also concerned that, because the young carer group was tenuously defined, it might be difficult to impress upon donors, sponsors, and others that new resources would need to be found for them. Some noted that there was a limit to the effectiveness of advocacy, especially with funders who were skeptical at the number of young carers requiring assistance. Hence, without research to support such activism, social agencies could lose credibility with funding sources for their current programs. Furthermore, it was evident that a shift was occurring within social service agencies toward creating a supportive community for their clients, whereby those with similar disadvantages find help and assistance from others in similar circumstances (Power, 2013).

Issues related to language/terminology and labeling of young carers may be more complicated than would initially appear. While a common terminology facilitates communication and common understanding, as well as the allocation of program resources, labeling of young people may have unintended consequences. If school-aged young people are labeled as young carers, this may increase the risk of bullying. Young carers may run the risk of becoming even more isolated because their life experience is more adult-like than other young people in school. Labeling young carers may also change their role from one that is informally expected within the family to that of a quasi-health care role with certain remunerative expectations.

The lack of policies and community supports for young carers in Canada's oil-rich province is disappointing, but not surprising given that young carers remain a hidden population. Where a group remains invisible, institutions and organizations are not readily able to develop systems and policies to address the needs of the group. Without recognition neither schools nor parents will be able to argue for support for young carers. Without support systems, young 
people will continue to carry this heavy burden and suffer in silence, bearing the negative consequences of caregiving at a young age. Moreover, the absence of young carer policies may be detrimental to these young people.

Young carers reach across several structural divides: social services, school services, legal system, religious organizations, and welfare systems. While agencies are successful in achieving their goals of assisting children and youth, they essentially operate as independent units, which limit their ability to reach across these structural divides. It would appear that social service policies tend to be uni-focused and do not address the multifaceted issues of young carers. This, paired with a lack of funding, resources and staff training, make it increasingly difficult to address the needs of young carers.

Programs for young carers are in their infancy across Canada. There are no known programs in the prairie provinces, Quebec, or the maritime provinces. Currently, four young carer programs are operational in Ontario and British Columbia. In Ontario, the Young Carers Initiative (YCIN) was established in 2003 by the Alzheimer Society of the Niagara Region. It has since evolved into a separate non-profit agency called the Young Carer Initiative (YCI) specifically established to provide educational and support services for young carers and their families. Subsequently, in 2008, the Powerhouse Project (PHP) was set up by YCI as a strategy to work across sectors with young people and families. This project offers a variety of supports including workshops, special events, a drop-in centre, a resource library, and respite services. The third project, Hospice Toronto, has established a Young Carers Program, the only one of its kind in a large urban centre. The Young Carers Program offers drop-in nights for young people, homework support, practical skills training, expressive arts, sports, and various field trips. It has developed a resource kit that is used to provide support to young people and families. In British 
Waugh et al.

Columbia, the Cowichan Family Caregivers Support Society on Vancouver Island operates the Youth Caregivers Project (YCP) that provides support to young carers and their families through a resource team comprised of young people and adults. The team also holds meetings with local school authorities and service providers in an attempt to encourage other programs to develop internal resources for young carers. The fourth program, in the Vancouver Island community of Campbell River, is also currently providing services to young carers.

Our study was exploratory in nature and has some limitations. The findings are limited to community agency perspectives on young carers and do not reflect the actual perspectives or experiences of young carers themselves. While the small number of agencies that volunteered to take part in study may not be representative of all community agencies who come in contact with young carers in Edmonton, the goal of this study was not to attain generalizability, but to describe the experience of agencies with young carers. Given that the discussion groups were not audiotaped so as to encourage candid dialogue, direct quotations of the discussions were not captured, thereby limiting the richness of the study data. The study findings may not be applicable to other settings where supports and services for young carers are more developed.

Research on young carers in Canada is in its infancy. While much is known about the issues and needs of young carers in other countries, Canadian data are lacking. In particular, prevalence data on young carers in Canada is needed. Whether the needs of young carers are being addressed by schools and community agencies also requires examination. The topic of young caregiving is a complex one, requiring examination of several different modalities, including current family structures, educational services, government contributions, and multidisciplinary, mixed methods research models. 
Care Gap for Young Carers

\section{Conclusion}

The predominant finding to emerge from our study with community agencies is that there is a major care gap for Edmonton's young carer population. Community organizations do not target their services at young carers and do not allocate resources to address their specific needs. Research is needed to determine the size and depth of the care gap and to ascertain what programs and policies should be developed to address this gap. Young carers are invisible, unrecognized, and lack support systems and policies within the Canadian context. Canada appears to lag considerably behind a number of other jurisdications around the world in recognizing and supporting young carers and services through public policy appear to be nonexistent. Terminology related to young carers is yet to be established among community agencies. Community resources are lacking to support the educational, informational and service needs of young carers and for staff training. Communication, collaboration and partnership between community agencies and policy makers are necessary in creating effective young carer policies. This study lays the foundation for more indepth research on the social and cultural needs of young people who provide supportive care for a family member. 
Waugh et al.

\section{References}

Aldridge, J. (2008). All work and no play? Understanding the needs of children with caring responsibilities. Children and Society, 22, 253-264. doi: 10.1111/j.10990860.2007.00094.x

Aldridge, J., \& Becker, S. (1993). Children as carers. Archives of Disease in Childhood, 69, 459462.

Aldridge, J., \& Becker, S. (1999). Children as carers: The impact of parental illness and disability on children's caring roles. Journal of Family Therapy, 21, 303-320.

Aldridge, J., \& Becker, S. (2003). Children caring for parents with mental illness: Perspectives of young carers, parent, and professionals. Bristol: The Policy Press.

Avison, W. R., Turner, R. J., Noh, S., \& Speechley, K. N. (1993). The impact of caregiving: Comparisons of different family contexts and experiences. In S. H. Zarit, L. I. Pearlin, \& K. W. Schaie (Eds.), Caregiving systems: Informal and formal helpers (pp. 75-105). Hillsdale, NJ: Erlbaum.

Banks, P., Cogan, N., Deeley, S., Hill, M., Riddell, S., \& Tisdall, K. (2001). Seeing the invisible children and young people affected by disability. Disability \& Society, 16(6), 797-814. doi: 10.1080/09687590120083967

Banks, P., Cogan, N., Riddell, S., Deeley, S., Hill, M., \& Tisdall, K. (2002). Does the covert nature of caring prohibit the development of effective services for young carers. British Journal of Guidance \& Counselling, 30(3), 229-246. doi: 10.1080/030698802100002281

Barber, M., \& Siskowski, C. (2008). Youth caregivers: Unrecognized providers of care. Pediatrics, 93(3), 488-494. doi: 10.1542/peds.2008-0093

Beards, C., \& Barua, K. (2011). Who are Australia's 'hidden' carers? Association of Relatives and Friends of the Mentally Ill. Retrieved from http://www.arafmi.org/article/who-areaustralia\%E2\%80\%99s-\%E2\%80\%98hidden\%E2\%80\%99-carers. Accessed on May 13, 2014.

Becker, S. (2000). Young carers. In M. Davies (Ed.), The Blackwell Encyclopedia of Social Work (pp. 378). Oxford: Blackwell.

Becker, S. (2007). Global perspectives on children's unpaid caregiving in the family: Research and policy on 'young carers' in the UK, Australia, the USA and Sub-Saharan Africa. Global Social Policy, 7(23), 23-50. doi: 10.1177/1468018107073892

Becker, S., Dearden, C., \& Aldridge, J. (2000). Young carers in the UK: Research, policy and practice. Research, Policy and Planning, 8(2), 13-22. 
Bittman, M., Fast, J. E., Fisher, K., \& Thomson, C. (2004). Making the invisible visible: The life and time(s) of informal caregivers. In M. Bittman \& N. Folbre (Eds.), Family time: The social organization of care (pp. 69-89). London, UK: Routledge.

Canadian Caregiver Coalition, (2012). Caregiver Facts. Retrieved from http://www.cccccan.ca/content.php?doc=43. Accessed on May 9, 2014.

Cass, B., Smith, C., Hill, T., Blaxland, M., \& Hamilton, M. (2009). Young carers in Australia: Understanding the advantages and disadvantages of their care giving. Social Policy Research Paper \#38. Australian Government Department of Families, Housing, Community Services and Indigenous Affairs. Retrieved from http://www.dss.gov.au/sites/default/files/documents/05_2012/sprp_38.pdf. Accessed May $16,2014$.

Chaparro, L. (2011). How a "special caring bond" is formed between the chronically ill patient and the family caregiver. AQUICHAN, 11(1) 7-22.

Charles, G. (2014). Position paper on young carers. Vancouver: BC Young Carers Research Group.

Charles, G., Marshall, S., \& Stainton, T. (2010). Demographics, profiles and initial results from the British Columbia Young Carers Study, Relational Child and Youth Care Practice, 23(4), 64-67.

Charles, G., Stainton, T., \& Marshall, S. (2009). Young carers in North America: Mature before their time. Reclaiming Children and Youth, 18(2), 38-41.

Charles, G., Stainton, T., \& Marshall, S. (2011). Young carers in immigrant families: An ignored population. Canadian Social Work, 12(1), 83-92.

Charles, G., Stainton, T., \& Marshall, S. (2012). Young carers in Canada: The hidden costs and benefits of young caregiving. Ottawa: Vanier Institute of the Family.

Cormac, I., \& Tihanyi, P. (2006). Meeting the mental and physical needs of carers. Advances in Psychiatric Treatment, 12, 162-172. doi: 10.1192/apt.13.3.162

Dearden, C., \& Becker, S. (1997). Protecting young carers: Legislative tensions and opportunities in Britain. Journal of Social Welfare and Family Law, 19(2), 123-138.

Diaz, N., Siskowski, S., \& Connors, L. (2007). Latino young caregivers in the United States: Who are they and what are the academic implications of this role? Child Youth Care Forum, 36, 131-140. doi: 10.1007/s10566-007-9040-4

Fast, J.E., Higham, B., Keating, N., Dosman, D., \& Eales, J. (2005) Family/friend caregiving and its consequences: Implications for the Compassionate Care Benefit Program. Final report to Human Resources and Skills Development Canada, Audit and Evaluation Directorate. 
Waugh et al.

Gates, M. F., \& Lackey, N. R. (1998). Youngsters caring for adults with cancer. Journal of Nursing Scholarship, 30, 11-5.

Giesbrecht, M., Crooks, V.A., Williams, A., Hankivsky, O. (2012). Critically examining diversity in end-of-life family caregiving: Implications for equitable caregiver support and Canada's Compassionate Care Benefit. International Journal for Equity in Health, 11, 65. doi:10.1186/1475-9276-11-65.

Hunt, G., Levine, C., \& Naiditch, L. (2005). Young caregivers in the U.S.: Findings from a national study. Washington D.C.: National Alliance for Caregiving.

Jenkins, S., \& Wingate, C. (1994). Who cares for young carers? British Medical Journal, 308, 733. doi: $10.1136 / \mathrm{bmj} .308 .6931 .733$

Kelly, L., \& Minty, A. (2007). End-of-life issues for aboriginal patients: A literature review. Canadian Family Physician 2007, 53(9): 1459-1465.

Kinley, A., \& Kolkman, J. (2009) Tracking the Trends 2009: Neighbourhood well-being in Edmonton. Edmonton: Edmonton Social Planning Council. Retrieved from https://www.edmontonsocialplanning.ca/index.php/resources/digital-resources/a-espcdocuments/a06-newsletters/14-tracking-the-trends-2009-neighbourhood-well-being-inedmonton/file. Accessed on May 13, 2014.

Lackey, N. R., \& Gates, M. F. (2001). Adults' recollections of the experiences as young caregivers of family members with chronic physical illnesses. Journal of Advanced Nursing, 34(3), 320-328.

McClure, L. (2001). School-age caregivers: Perceptions of school nurses working in central England. The Journal of School Nursing, 17, 76. doi: 10.1177/105984050101700204

Merrell, J., Kinsella, F., Murphy, F., Philpin, S., \& Ali, A. (2005). Support needs of carers of dependent adults from a Bangladeshi community. Journal of Advanced Nursing, 51(6), 549-557.

Metzing-Blau, S., \& Schnepp, W. (2008). Young carers in Germany: To live on as normal as possible - a grounded theory study. BMC Nursing, 7, 15. doi: 10.1186/1472-6955-7-15

Moore, T., McArthur, M., \& Noble-Carr, D. (2011). Different but the same? Exploring the experiences of young people caring for a parent with an alcohol or other drug issue. Journal of Youth Studies, 14(2), 161-177.

Morse, J. Q., Shaffer, D. R., Williamson, G.M., Dooley, W. K., Schulz, R. (2012). Models of self and others and their relation to positive and negative caregiving responses. Psychology and Aging, 27(1), 211-218.

Pakenham, K. I., Chiu, J., Bursnall, S., \& Connon, T. (2007). Relations between social support, appraisal and coping and both positive and negative outcomes in young carers. Journal of Health Psychology, 12(1), 89-102. doi: 10.1177/1359105307071743 
Payne, G., \& Payne, J. (2013). Key Concepts in Social Research. Sage Research Methods. Retrieved from: http://srmo.sagepub.com/view/key-concepts-in-social-research/n21.xml. Doi:http://dx.doi.org/10.4135/9781849209397. Accessed on May 13, 2014.

Power, A. (2013) Making space for belonging: Critical reflections on the implementation of personalized adult social care under the veil of meaningful inclusion. Social Science and Medicine, 88, 68-75.

Richardson, K., Jinks, A., \& Roberts, B. (2009). Qualitative evaluation of a young carers' initiative. Journal of Child Health Care, 13(2), 150-160. doi: $10.1177 / 1367493509192475$

Ridge, T. (2011). The everyday costs of poverty in childhood: A review of qualitative research exploring the lives and experiences of low-income children in the UK. Children \& Society, 25(1), 73-84.

Schulz, R., \& Beach, S. R. (1999). Caregiving as a risk factor for mortality: The caregiver health effects study. Journal of the American Medical Association, 282, 2215-2219.

Schulz, R., \& Quittner, A. L. (1998). Caregiving for children and adults with chronic conditions: Introduction to the special issue. Health Psychology, 17, 107-111.

Shifren, K., \& Kachorek, L. V. (2003). Does early caregiving matter? The effects on young caregivers' adult mental health. International Journal of Behavioral Development, 27(4), 338-346.

Siskowski, C. (2006). Young caregivers: Effects of family health situations on school performance. The Journal of School Nursing, 22(3), 163-169. doi: 10.1177/10598405060220030701

Smyth, C., Blaxland, M., \& Cass, B. (2011). 'So that's how I found out I was a young carers and that I actually had been a carer most of my life'. Identifying and supporting hidden young carers. Journal of Youth Studies, 14(2), 145-160. doi: 10.1080/13676261.2010.506524

Statistics Canada. (2006). Participation and activity limitations survey 2006: Analytical report. The 2006 Participation and Activity Limitations Survey: Disability in Canada. No. 2 Statistics Canada Catalogue no. 89-628-X. Ottawa.

Statistics Canada. Focus on Geography Series, 2011 Census. Census metropolitan area of Edmonton, Alberta. Retrieved from http://www12.statcan.ca/censusrecensement/2011/as-sa/fogs-spg/Facts-cmaeng.cfm?LANG=Eng\&GK=CMA\&GC=835. Accessed on May 10, 2014.

Stewart, F. \& Patterson, E. (2010). Caring in Scotland: Analysis of existing data sources on unpaid carers in Scotland. Edinburgh: Scottish Government Social Research. Retrieved from http://www.scotland.gov.uk/Resource/Doc/319592/0102111.pdf. May 16, 2014. 
Waugh et al.

Taylor, V., \& Fuggle, P. (2001). Well sibling psychological adjustment to chronic physical disorder in a sibling: How important is maternal awareness of their illness attitudes and perceptions? Journal of Child Psychology and Psychiatry, 42(7), 953-962.

The Association for Qualitative Research (2013). Group Discussion. The Hub of Qualitative Thinking. Retrieved from www.aqr.org.uk/glossary/?term=groupdiscussion. Accessed on May 13, 2014.

Thomas, N., Stainton, T., Jackson, S., Cheung, W. E., Doubtfire, S., \& Webb, A. (2003). 'Your friends don't understand': Invisibility and unmet need in the lives of 'young carers'. Child and Family Social Work, 8, 35-46.

Warren, J. (2007). Young carers: Conventional or exaggerated levels of involvement in domestic and caring tasks. Children \& Society, 21, 136-146. doi: 10.1111/j.10990860.2006.00038.x

Yasmin, R., Charles, G., \& Marshall, S. (2012). An analysis of responsibility, attachment security, and relationship efficacy among young carers. Relational Child and Youth Care Practice, 25(2), 48-56. 